\title{
Inbreeding and epigenetics: beneficial as well as deleterious effects
}

\section{Daniel W. Nebert, Marina Gálvez-Peralta, Zhanquan Shi and Nadine Dragin}

The correspondence article by Christian Biémont (Biémont, C. Inbreeding effects in the epigenetic era. Nature Rev. Genet. 11, $234(2010))^{1}$ and the articles (Charlesworth, D. \& Willis J. H. The genetics of inbreeding depression. Nature Rev. Genet. 10, 783-796 $(2009)^{2,3}$ he discusses deserve further dialogue. These papers summarized the theoretical basis of inbreeding depression, defined as the deleterious effects that result from crossing related individuals. Rather than this phenomenon being the result of DNA sequence alterations, Biémont puts forth a strong argument ${ }^{1}$ that inbreeding depression probably results from epigenetic mechanisms - that is, chromosomal events in which DNA sequence is not altered. Epigenetic mechanisms include cell-specific DNA hyper- and hypomethylation $^{4}$, RNA interference ${ }^{5}$, histone modifications ${ }^{6}$, chromatin remodelling ${ }^{7}$ and canalization/decanalization ${ }^{8}$.

Our laboratory has observed the opposite of inbreeding depression - that is, inbreeding de-repression'. This can be defined as the beneficial effects that result from crossing related individuals. By inbreeding a freshly generated knockout mouse line, we found that subsequent generations produced much healthier viable offspring compared with the $\mathrm{F}_{1}$ generation.

Cytochrome $\mathrm{P} 450$ genes, or at least those members in the Cyp1, Cyp2, Cyp3 and Cyp4 gene families ${ }^{9}$, are commonly perceived as liver enzymes that metabolize drugs and environmental chemicals. However, most if not all of the CYP1 to CYP4 enzymes exist in many cell types and have important endogenous roles. Among other functions, these enzymes participate in eicosanoid synthesis and/or degradation ${ }^{9,10}$ and therefore are probably crucial upstream determinants of innumerable cellular processes, from vascular or airway constriction/relaxation to tumour progression and cancer metastasis ${ }^{10}$.

Our laboratory generated the Cyp1a1Cyp1a2-Cyp1b1 $1^{-/-}$triple-knockout mouse by crossing various combinations of female versus male Cyp1a1-Cyp1a2 $2^{+/}$doubleknockout heterozygotes with $C y p 1 b 1^{+/-}$ single-knockout heterozygotes. From 150 $\mathrm{F}_{1}$ litters examined, 58 Cyp1a1-Cyp1a2Cyp $1 \mathrm{bl}^{-/-}$pups survived to birth, and only two females and one male lived to adulthood and were able to breed successfully ${ }^{11}$. Incomplete-penetrance phenotypes seen in the $\mathrm{F}_{1}$ generation included embryolethality, slower weight gain, hydrocephalus, hermaphroditism and cystic ovaries ${ }^{11}$. All of these phenotypes are consistent with eicosanoid-mediated processes ${ }^{10,11}$.

Most intriguingly, as we continued to breed the triple-knockout $\mathrm{F}_{1}$ homozygote survivors, the embryolethality, the lower weight and all of the above-mentioned birth defects disappeared quickly. We believe that these findings represent the action of natural selection - that is, only the healthiest animals survived and were able to breed the subsequent generation. Because this inbreeding de-repression phenomenon happened within just two to four generations, we presume it reflects epigenetic rather than genetic changes in the genome. Although we suspect this also has occurred with other knockout mouse lines, we are not aware of this ever having been reported.

In conclusion, inbreeding can lead not only to depression but also to an improved, healthier, viable phenotype. And, in all likelihood, both deleterious and beneficial traits that appear during brother-sister inbreeding are caused by epigenetic rather than genetic mechanisms.

Daniel W. Nebert, Marina Gálvez-Peralta, Zhanquan

Shi and Nadine Dragin are at the Department of Environmental Health and the Center for Environmental Genetics (CEG), University Cincinnati Medical Center, Cincinnati, Ohio 45267-0056, USA

Daniel W. Nebert is also at the Division of Human Genetics, Department of Pediatrics and Molecular \& Developmental Biology, Cincinnati Children's Hospital, Eland and Bethesda Avenues, Cincinnati, Ohio 452292899, USA.

Correspondence to D.W.N. e-mail:dan.nebert@uc.edu

doi: 10.1038/nrg2664-c2

1. Biêmont, C. Inbreeding effects in the epigenetic era. Nature Rev. Genet. 11, 234 (2010).

2. Charlesworth, D. \& Willis J. H. The genetics of inbreeding depression. Nature Rev. Genet. 10, 783-796 (2009).

3. Kristensen, T. N., Pedersen, K. S., Vermeulen, C. J. \& Loeschcke, V. Research on inbreeding in the 'omic' era. Trends Ecol. Evol. 25, 44-52 (2009).

4. Zuo, T., Tycko, B., Liu, T. M., Lin, H. J. \& Huang, T. H. Methods in DNA methylation profiling. Epigenomics 1, 331-345 (2009)

5. Mohr, S., Bakal, C. \& Perrimon, N. Genomic screening with RNAi: results and challenges. Annu. Rev. Biochem. 79, 37-64 (2010).

6. Mosammaparast, N. $\&$ Shi, Y. Reversal of histone methylation: biochemical and molecular mechanisms of histone demethylases. Annu. Rev. Biochem. 79, 155-179 (2010)

7. Ho, L. \& Crabtree, G. R. Chromatin remodelling during development. Nature 463, 474-484 (2010).

8. Gibson, G. Decanalization and the origin of complex disease. Nature Rev. Genet. 10, 134-140 (2009).

9. Nebert, D. W. \& Russell, D. W. Clinical importance of the cytochromes P450. Lancet 360, 1155-1162 (2002).

10. Nebert, D. W. \& Karp, C. L. Endogenous functions of the aryl hydrocarbon receptor (AHR): intersection of cytochrome P450 1 (CYP1) metabolized eicosanoids and AHR biology. J. Biol. Chem. 283, 36061-36065 (2008).

11. Dragin, N., Shi, Z. Q., Madan, R., Karp, C. L., Sartor, M. A. Chen, C. Gonzalez, F. J. \& Nebert, D. W. Phenotype of the Cyp 1a1/1a2/1b1(-/) triple-knockout mouse. Mol. Pharmacol. 73, 1844-1856 (2008).

Competing interests statement

The authors declare no competing financial interests. 